\title{
A tarefa de traduzir o passado.
}

\section{Luciana Silviano Brandão Lopes, UFMG}

Resumo: O presente texto tenta fazer uma conexão entre o trabalho de tradução, tal qual Walter Benjamin o vê, e o trabalho que o escritor tem ao escrever uma narrativa de testemunho, pois o intraduzível está tanto na base de uma língua a ser traduzida, como no mais íntimo de uma narrativa de testemunho.

Palavras-chave: tradução; trauma; testemunho.

É possível comparar a tarefa do tradutor, tal como Walter Benjamin a descreve, e a tarefa do escritor de testemunho? A meu ver, o escritor ao transpor para o papel suas experiências de vida, também faz um trabalho de tradução, pois tenta colocar em palavras um texto que, com o passar dos anos, se tornou estrangeiro.

\section{A tarefa do tradutor}

A Tarefa do Tradutor, de Walter Benjamin, foi escrito em 1923 e agrupa-se a outros ensaios nos quais o filósofo trabalha sua teoria da linguagem, tais como Sobre a Linguagem em Geral e sobre a Linguagem dos Homens (1916) e A Doutrina do Semelhante e Sobre a Faculdade Mimética (1933).

Die Aufgabe des Übersetzers (A Tarefa do Tradutor) foi publicado como prefácio da tradução dos Tableaux Parisiens de Baudelaire. Interessante pensar no título desse ensaio, pois o verbo aufgeben, do qual provém o substantivo Aufgabe, significa entregar, no duplo sentido do termo: dar algo a alguém para que cuide disso (entregar uma carta ao correio), mas também dar algo a alguém, abrindo mão da posse do objeto (entregar uma cidade ao inimigo). Desta forma, Aufgabe apresenta uma nuança semântica que transita entre o dom, o dado e a renúncia ou abandono do tradutor. Pode-se dizer que a primeira renúncia ligada à tarefa de traduzir refere-se às implicações entre traduzido e comunicado, pois traduzir uma língua não significa torná-la comunicável ou acessível. Para Benjamin, o que uma tradução deveria passar é o inapreensível, o misterioso, o poético, quer dizer, aquilo que é essencial à obra, pois "nenhum poema dirige-se, pois, ao leitor, nenhum quadro, ao espectador, nenhuma sinfonia, aos ouvintes". ${ }^{1}$

De acordo com Benjamin, a tradução é apenas uma forma provisória de lidar com a estranheza das línguas e, através dela, "o original cresce e se alça a uma atmosfera, por assim dizer, mais elevada e mais pura da língua, onde, é claro, não poderá viver por muito tempo [...]". ${ }^{2}$ A finalidade da tradução seria dar expressão à relação mais íntima das línguas umas com as outras, em direção à língua pura, o que daria acesso a alguma coisa que nenhuma língua poderia alcançar isoladamente. No entanto, o essencial do original, o inapreensível, continua a ressoar nos limites de toda tradução, esse núcleo guarda a lei da tradução, a sua exigência e, também, aquilo que não pode ser novamente traduzido: "Subtraia-se da tradução o que se puder em termos de informação e tente-se traduzir isso: ainda assim, restará o intocável no texto aquilo a que se dirigia o trabalho do verdadeiro tradutor." 3 
Revelar o intraduzível, deixar pulsar o estrangeiro no texto traduzido, seria essa a tarefa a que se destina a tradução? Ao mesmo tempo em que a obra resiste à tradução, através da figura do núcleo essencial, não deixa de exigi-la. Ao ser transposta para outra língua, através de uma forma que visaria a língua pura e, ao operar a tradução, o núcleo essencial é transferido integralmente. O inapreensível, dessa forma, é deslocado, em sua literalidade, para o interior da língua traduzida.

Segundo Benjamin, o poder da tradução é “[...] transformar o simbolizante no próprio simbolizado, recobrar a pura língua plasmada no movimento da linguagem [...]". ${ }^{4}$ Portanto, a "tarefa do tradutor é redimir, na própria língua, a pura língua, exilada na estrangeira, liberar a língua do cativeiro da obra por meio da criação." ${ }^{5}$ Desta forma, o que o Benjamin propõe é:

[...] - Sendo assim, o que resta de significativo para o sentido na relação entre tradução e original pode ser apreendido numa comparação: da mesma forma como a tangente toca a circunferência de maneira fugidia e em um ponto apenas, sendo esse contato, e não o ponto, que determina a lei segundo a qual continua sua via reta para o infinito, a tradução toca fugazmente, e apenas no ponto infinitamente pequeno do sentido do original, para perseguir, segundo a lei da fidelidade, sua própria vida no interior da liberdade do movimento da língua. ${ }^{6}$

Muitos teóricos escreveram sobre esse importante, e por vezes, considerado enigmático, ensaio de Walter Benjamin. Dentre eles, podem-se citar Paul de Man, Jacques Derrida, e aqui no Brasil, Haroldo de Campos, Jeanne Marie Gagnebin e Suzana Kampff Lages.

Gostaria, de fazer um recorte dos ensaios Sobre a linguagem em geral e sobre a linguagem do homem e A tarefa do tradutor, para nos auxiliar na discussão sobre a possibilidade de comparação da tarefa do tradutor e a tarefa do escritor de testemunho e para isso, utilizarei como referência os escritos de Suzana Kampff Lages e Jeanne Marie Gagnebin.

Em Walter Benjamin: Tradução e Melancolia, Suzana Kampff Lages discute exaustivamente o ensaio sobre a tradução e o sobre a linguagem de Benjamin. Segundo a autora, o filósofo considerava o texto sobre a linguagem como "arcano" de seu pensamento e, nele, pode-se encontrar em germe, reflexões desenvolvidas no escrito sobre a tradução. No primeiro, Benjamin utiliza-se de uma noção de tradução para explicar a natureza da linguagem e no posterior, faz o caminho inverso, pressupõe uma certa noção de linguagem para a explicar a natureza da tradução. Lages, ao comentar a transformação do pensamento benjaminiano nos dois escritos, afirma que

[...] segundo o ensaio sobre a linguagem, na própria origem da linguagem humana estaria uma operação de tradução, anterior mesmo às próprias línguas: tradução no âmbito mudo da natureza para o domínio "falante" da linguagem. Por sua vez, o ensaio sobre o tradutor parte dessa desorganização babélica inicial para postular o resgate messiânico dessa condição decaída, da pura língua - não como língua mítica do paraíso, que constitui anterioridade absoluta, mas como aquilo a que visam tendencialmente todas as línguas. ${ }^{7}$ 
Essa asserção possibilita pensar que tradução e testemunho podem ter ligação, se considerarmos o testemunho como uma tradução do fato traumático, do que ficou para trás e de certa forma, sem fazer parte da linguagem.

\section{Testemunho}

Testemunho no Dicionário Eletrônico Houaiss, significa "declaração, depoimento de uma ou mais testemunhas, afirmação fundamentada, depoimento, comprovação", o que leva a crer se tratar de asserção baseada em fatos reais, que aconteceram na realidade e que podem ser comprovados. No mundo atual percebe-se uma profusão de narrativas de si, seja em blogs, redes sociais, testemunhos televisivos ou realities shows. Mesmo no campo da literatura, há uma proliferação de publicações de autobiografias, jornais íntimos, diários, depoimentos. Mas, afinal o que é o testemunho? Todo relato tem valor de testemunho?

Em latim, há dois termos usados para designar testemunha: testis e superstes. $\mathrm{O}$ primeiro "significa etimologicamente aquele que se põe como terceiro em um processo ou em um litígio entre dois contentores". ${ }^{8} \mathrm{O}$ segundo, "indica aquele que viveu algo, atravessou até o final um evento e pode, portanto, dar testemunho disto", ${ }^{9}$ nessa perspectiva, o superstes é aquele que é testemunha ativa no processo. No grego, testemunha é martis, termo usado pelos primeiros Padres da Igreja para designar a morte dos cristãos perseguidos que, dessa forma, davam testemunho de sua fé. Para Primo Levi, as verdadeiras testemunhas, longe de serem mártires, são aqueles que não sobreviveram para contar a história, são os que morreram e não conseguiram dar o seu testemunho: "Repito, não somos nós, os sobreviventes, as autênticas testemunhas. [...] Quem o fez, quem fitou a gorgora, não voltou para contar, ou voltou mudo; mas são eles, os "muçulmanos", os que submergiram - são eles as testemunhas integrais, cujo depoimento teria significado geral". ${ }^{10}$ Portanto, quem sobreviveu e deu seu testemunho o fez "em nome de terceiros", sua narrativa não foi experimentada pessoalmente, pois a "demolição levada a cabo, a obra consumada, ninguém a narrou, assim como ninguém jamais voltou para contar a sua morte". ${ }^{11}$

Giorgio Agamben, referindo-se à problemática do testemunho dos sobreviventes de campo de concentração, afirma:

A testemunha comumente testemunha a favor da verdade e da justiça, e delas a sua palavra extrai consistência e plenitude. Nesse caso, porém, o testemunho vale essencialmente por aquilo que nele falta; contém, no seu centro, algo intestemunhável, que destitui a autoridade dos sobreviventes. As "verdadeiras" testemunhas, as "testemunhas integrais" são as que não testemunharam, nem teriam podido fazê-lo. São os que "tocaram o fundo", os muçulmanos, os submersos. Os sobreviventes, como pseudotestemunhas, falam em seu lugar, por delegação: testemunham sobre um testemunho que falta [...]. Quem assume para si o ônus de testemunhar por eles, sabe que deve testemunhar pela impossibilidade de testemunhar [... ${ }^{12}$

Conclui-se, a partir do que foi exposto, que o testemunho sempre carrega algo do impossível em seu cerne, pois é encontro com a catástrofe, com o real, com a morte. Então, como fazer para testemunhar, já que o testemunho verdadeiro pertence apenas aos mortos? 


\section{A escrita ou a vida}

O escritor espanhol Jorge Semprún Maura (1923/2011), pode-se dizer, viveu como testemunha dos grandes acontecimentos históricos do século XX. Lutou contra o fascismo, foi militante da resistência e teve a terrível experiência dos campos de concentração, viveu a ilusão comunista e suas fraturas - ao serem revelados os campos de concentração comunistas, como Gulag. Nasceu em Madri, em uma família de classe média alta. Em 1939, após ter vivido em Haia o período de tempo em que, na Espanha, acontecia a Guerra Civil, e depois que Franco subiu ao poder, exilou-se com sua família na França, onde estudou filosofia na Universidade Sorbonne. Com a ocupação nazista na Europa, Semprún aderiu à resistência e filiou se ao PCE (Partido Comunista da Espanha), em 1942, sendo depois disso capturado e levado a Buchenwald ${ }^{131}$, onde permaneceu por quase dois anos.

Seu livro de memórias, A escrita ou a vida, foi escrito anos após sua libertação do campo de concentração. Em 1994 o escritor decidiu quebrar seu silêncio sobre o campo e, desta vez, sem usar a ficção como aliada, lançou A escrita ou a vida. A narrativa do livro se inicia com a chegada, em abril de 1945, das tropas do general Patton a Buchenwald e a libertação de seus prisioneiros. A história contada não segue uma ordem cronológica e, muitas vezes, é difícil para o leitor orientar-se no tempo, não se sabendo a ordem exata dos acontecimentos. A passagem na qual o autor conta que a feitura do livro é confusa, dando a impressão de que foi escrito aos pedaços, iniciado e interrompido por diversas vezes.

Com o fim da guerra e libertado do campo, Semprún voltou à França, mas, atormentado pelas memórias terríveis de seu encarceramento, decidiu calar-se. Seria possível falar sobre o cheiro adocicado de carne humana queimada, da fumaça do crematório que afugentava os pássaros, dos corpos que se decompunham em escala industrial? Parecia que essas experiências eram intransmissíveis e sua revivificação, mortífera. Portanto, o silêncio significava sobrevivência. Cito-o:

À primeira vista, nada indicava onde eu havia passado os últimos anos. Eu mesmo logo me calei a respeito, por muito tempo. Não com um silêncio afetado, nem culpado, tampouco temeroso. Silêncio de sobrevivência, melhor dizendo. Silêncio ruidoso do apetite de viver. Não fiquei, pois, mudo como um túmulo. Mudo porque deslumbrado com a beleza do mundo, com suas riquezas, desejoso de nele viver apagando os traços de uma agonia indelével. ${ }^{14}$

Interessante pensar no título do livro, pois não se trata da escrita como defesa ou libertação diante da morte e sim, do contrário, é a escrita que pode levar à morte:

Tudo recomeçaria, depois daquela felicidade, daquelas mil felicidades mínimas e dilacerantes. Tudo recomeçaria enquanto eu estivesse vivo: assombração na vida, melhor dizendo. Enquanto estivesse tentado a escrever. A felicidade da escrita, eu começava a saber, jamais apagava essa desgraça da memória. Muito pelo contrário: aguçava-a, escavava-a, reavivava-a. Tornava-a insuportável. ${ }^{15}$

O indizível está próximo do intestemunhável, termo designado por Giorgio Agamben, quando se refere à noção de testemunho dos prisioneiros de campos de concentração nazista: "o verdadeiro testemunho vale essencialmente por aquilo que 
lhe falta; ele porta em seu coração o "intestemunhável". ${ }^{16}$ Como já dito, existem fatos ocorridos na vida de um indivíduo que estão na vertente do indizível, do inenarrável, do intestemunhável, pois a linguagem é incompleta, é não - toda. Por esta razão, vale lembrar uma passagem do livro de Semprún, em que o escritor relata uma conversa com seus companheiros de campo sobre a necessidade e a dificuldade em revelar a experiência em Buchenwald:

O problema não é esse - logo exclama outro - O verdadeiro problema é não é contar, quaisquer que sejam as dificuldades. É escutar... Vão querer escutar as nossas histórias, mesmo que sejam bem contadas?

Portanto, não sou o único a me formular essa pergunta. É verdade que ela se impõe por si mesma.

Mas, instala-se a confusão. Todos têm uma opinião a dar. Não poderei transcrever a conversa como deveria, identificando os participantes.

- O que é que isso quer dizer, "bem contadas"? - indigna-se alguém. - Tem que se dizer as coisas como elas são, sem artifícios!

É uma afirmação peremptória que parece aprovada pela maioria dos futuros repatriados presentes. Dos futuros narradores possíveis. Então, apresento-me, para dizer o que me parece uma obviedade.

- Contar bem quer dizer: de modo a sermos escutados. Não conseguiremos sem um pouco de artifício. Artifício suficiente para que se torne arte! ${ }^{17}$

A escrita, no caso de Semprún, teve função de, pode-se dizer, expiação. Ao finalmente tomar da pena e escrever, algo do indizível pôde ser construído, bordado no furo do real da morte.

\section{O processo de resgate da memória}

Wander de Melo Miranda utiliza duas citações para descrever o processo de resgate do fato passado, no primeiro, lembra Beckett, que num estudo sobre Proust ${ }^{18}$ afirma que:

Proust tinha má memória [...] O homem de boa memória nunca se lembra de nada, porque nunca se esquece de nada. Sua memória é uniforme, uma criatura de rotina, simultaneamente condição e função de seu hábito impecável, um instrumento de referência e não um instrumento de descoberta. A apologia de sua memória - "Lembro-me como se fora ontem..."- é também seu epitáfio e indica a expressão exata de seu valor. ${ }^{19}$

No segundo, cita Deleuze e Guattari, quando discutem os "blocos de infância" de Kafka. $^{20}$

A memória de Kafka nunca foi boa; tanto melhor, pois a lembrança de infância é incuravelmente edipiana, impele e bloqueia o desejo em uma foto, rebate a cabeça de desejo e o corta de todas as suas conexões [...] A lembrança opera uma reterritorialização da infância. ${ }^{21}$

Há uma diferença fundamental entre as duas tendências, afirma ele, uma propõe que é necessário esquecer para lembrar, e a outra, que é necessário esquecer de 
lembrar, no entanto, nas duas “é colocado em questão o papel desempenhado pela memória do Mesmo, pela lembrança que conduz quem lembra à edificação de um monumento de si (...)." ${ }^{22}$ A memória, nesse caso atuaria como duplo do eu e imporia ao sujeito que lembra a falsa consciência da sua plenitude e autonomia, "condenando-o a refazer o tecido de sua história sempre com os mesmos fios de um único e imutável trançado o qual, por não conter os fios que o Outro tece, é irremediavelmente alienante." 23 Por outro lado, no caso da memória operadora da diferença, o processo é de descobrimento, desconstrução, desterritorialização, processo produtivo que "tece com as idéias e imagens do presente a experiência do passado." 24

\section{Uma tentativa de conclusão}

É possível comparar a tradução e o escrito de testemunho? Existe algum ponto em comum entre eles? Importante lembrar-se da reflexão de Santo Agostinho sobre a natureza paradoxal do tempo:

De que modo existem aqueles dois tempos - o passado e o futuro - se o passado já não existe e o futuro ainda não veio? Quanto ao presente, se fosse sempre presente e não passasse para o pretérito, já não seria tempo mas eternidade. Mas se o presente, para ser tempo, tem necessariamente de passar para o pretérito, como podemos afirmar que ele existe, se a causa de sua existência é a mesma pela qual deixará de existir? Para que digamos que o tempo verdadeiramente só existe porque tende a não ser? ${ }^{25}$

Parece que o tempo é como a memória, que só se alcança em outro lugar, de outra forma, jamais onde a imaginamos estar, pois é matéria fugidia. Para alcançá-la é necessário lançar mão de subterfúgios, de usar a imaginação, pois lá onde está é inalcançável. Da mesma forma, a tradução também é algo diferente, "uma tradução não é mais o texto original, passado, e não chega ainda a ser um novo texto, completamente autônomo, pois ainda se vincula de alguma forma, ao texto a partir do qual foi criada." 26

Simultaneamente excessivo e carente, poderoso e impotente, sempre o mesmo texto e sempre um outro, o texto de uma tradução destrói aquilo que o define como original - sua língua - e o faz reviver por intermédio de uma outra língua, estranha, estrangeira". ${ }^{27}$

O texto da memória também está lá, no passado, tal como ocorreu, mas ao ser transposto para o presente algo de sua inenarrabilidade se faz evidente através da impossibilidade da tradução. Da mesma forma que o tradutor, poderíamos afirmar, o escritor trabalha com uma nova língua, diferente da do original.

Abstract: The present text tries to make a connection between the work of translation, as Walter Benjamin views it, and the work that a writer has when writing a auto-biographical text. Every language as well as a testimonial narrative have an untranslatable core. 
Keywords: translation; trauma; testimony.

\section{Referências Bibliográficas}

AGAMBEN, Giorgio. O que resta de Auschwitz: o arquivo e a testemunha: homo saccer III. São Paulo: Boitempo, 2008.

AGOSTINHO, Santo. Confissões. 9. ed. Petrópolis, Vozes, 1988.

BECKET, Samuel. Proust. Trad. Arthur Nestrovski. Porto Alegre: L\&PM, 1986.

BENJAMIN, Walter. Escritos sobre mito e linguagem. São Paulo: Duas Cidades; ed. 34, 2011.

LAGES, Susana Kampff. Walter Benjamin: Tradução e Melancolia. São Paulo: Editora da Universidade de São Paulo, 2007.

LEVI, Primo. Os afogados e os sobreviventes: os delitos, os castigos, as penas, as impunidades. Rio de Janeiro: Paz e Terra, 1990.

MIRANDA, Wander Melo. Corpos escritos: Graciliano Ramos e Silviano Santiago. São Paulo: EDUSP; Belo Horizonte: Ed. UFMG, 1992.

PEREC, George. W ou a memória da infância. Trad. P. Neves. São Paulo: Companhia das Letras, 1995

SEMPRUM, Jorge. A escrita ou a vida. São Paulo, SP: Ed. Companhia das Letras, 1995.

\section{Notas}

${ }^{1}$ BENJAMIN, 1923, p. 101.

${ }^{2}$ BENJAMIN, 1923, p. 110.

${ }^{3}$ BENJAMIN, 1923, p. 110.

${ }^{4}$ BENJAMIN, 1923, p. 116.

${ }^{5}$ BENJAMIN, 1923, p. 117.

${ }^{6}$ BENJAMIN, 1963, p. 117.

${ }^{7}$ LAGES, 2007, p. 214.

${ }^{8}$ AGAMBEN, 2008, p. 27.

${ }^{9}$ AGAMBEN, 2008, p.27.

${ }^{10}$ LEVI, 1990, p. 47.

${ }^{11}$ LEVI, 1990, p. 47.

12 AGAMBEN, 2008, p. 43. 
${ }^{13} \mathrm{O}$ campo de concentração de Buchenwald está localizado na Alemanha, a oito quilômetros da cidade de Weimar. Foi um campo de trabalhos forçados diferentemente de outros, que eram de extermínio.

${ }^{14}$ SEMPRÚN, 1995, p. 110.

${ }^{15}$ SEMPRÚN, 1995, p. 160.

${ }^{16}$ AGAMBEN, 2008, p. 43.

${ }^{17}$ SEMPRÚN, 1995, p. 125.

${ }^{18}$ MIRANDA, 1992, p.119.

${ }^{19}$ BECKET, 1986, p.23.

${ }^{20}$ DELEUZE E GUATARRI, p.114.

${ }^{21}$ MIRANDA, 1992, p.120.

${ }^{22}$ MIRANDA, 1992, p.120.

${ }^{23}$ MIRANDA, 1992, p.120.

${ }^{24}$ MIRANDA, 1992, p. 120.

${ }^{25}$ AGOSTINHO, 1988, p. 278.

${ }^{26}$ LAGES, 2007, p. 215.

${ }^{27}$ LAGES, 2007, p. 215. 